\section{BIOSYNTHESIS OF MANUMYCIN: ORIGIN OF THE POLYENE CHAINS}

\author{
RAlF Thiericke and Axel ZeECK* \\ Institut für Organische Chemie, \\ Universität Göttingen, \\ Tammannstr. 2, D-3400 Göttingen, FRG
}

(Received for publication September 7, 1987)

Manumycin ${ }^{1 \sim 3)}$ and the closely related manumycin-group antibiotics ${ }^{4 \sim 6)}$ consist of structural units obviously derived from different biosynthetic pathways. For example, the 2-amino-3hydroxycyclopent-2-enone moiety in manumycin (1) may well be biosynthesized from succinate and glycine via an intramolecular cyclization of 5-aminolevulinic acid as Floss et al. ${ }^{\text {?) }}$ found for the antibiotic asukamycin. In this communication we describe the incorporation of $\left[{ }^{13} \mathrm{C}\right]$ acetate into manumycin (1). This allowed the biosynthetic source of the methyl-branched $\mathrm{C}_{13}$ side chain and the triene chain to be determined. The remaining multifunctional, meta-substituted, six-membered ring carries a nitrogen and an additional carbon atom; the incorporation pattern of acetate into this $m-C_{7} \mathrm{~N}$ unit is also reported.
Experiments were carried out using cultures of the manumycin producer, Streptomyces parvullus (strain Tü 64), grown at $28^{\circ} \mathrm{C}$ in 1,000 $\mathrm{ml}$ Erlenmeyer flasks filled with $100 \mathrm{ml}$ of medium (degreased soybean mean $2 \%$, mannitol $2 \%, \mathrm{pH}$ adjusted to 7.0 ). Precursors, which were dissolved in small amounts of deionized water and adjusted to $\mathrm{pH} 7.0$ with $1 \mathrm{M} \mathrm{NaOH}$, were added into the stationary growing phase ${ }^{22}$ about 40 hours after inoculation. Both the $\left[1-{ }^{13} \mathrm{C}\right]$ acetate and $\left[2-{ }^{13} \mathrm{C}\right]$ acetate precursor experiments were carried out using $4 \times 100 \mathrm{ml}$ of culture medium and an amount of $10.8 \mathrm{mmol} /$ liter of labeled acetate. The culture broth was adjusted to $\mathrm{pH} 4.5,34$ hours later and centrifuged $(3,000 \mathrm{rpm}, 30$ minutes). The mycelium was extracted twice with acetone. After evaporation the remaining water residue was extracted with $\mathrm{CHCl}_{3}$. Evaporation of the organic layer resulted in a dark red crude product which was chromatographed twice on a Sephadex LH-20 column $\left(80 \times 2.5 \mathrm{~cm}, \quad \mathrm{CHCl}_{3}\right)$. The purified pale yellow manumycin (1) (yield: $25.3 \mathrm{mg} / \mathrm{liter}$ of $\left[1{ }^{13} \mathrm{C}\right]$ acetate labeled $1 ; 48.0 \mathrm{mg} /$ liter of $\left[2-{ }^{13} \mathrm{C}\right]$ acetate labeled 1) corresponded completely with an authentic sample ${ }^{2)}$.

Based on the NMR signal assignments of manumycin $(\mathbf{1})^{2)}$, the ${ }^{13} \mathrm{C}$ NMR spectra of $\left[1-{ }^{-13} \mathrm{C}\right]$ acetate (Fig. 1) and $\left[2-{ }^{13} \mathrm{C}\right]$ acetate enriched

Fig. 1. Proton decoupled ${ }^{13} \mathrm{C}$ NMR spectra of $\left[1{ }^{13} \mathrm{C}\right]$ acetate-enriched manumycin (1) (A) and reference sample (B) recorded at $50.3 \mathrm{MHz}$ in $\mathrm{CDCl}_{3}$.

(A)

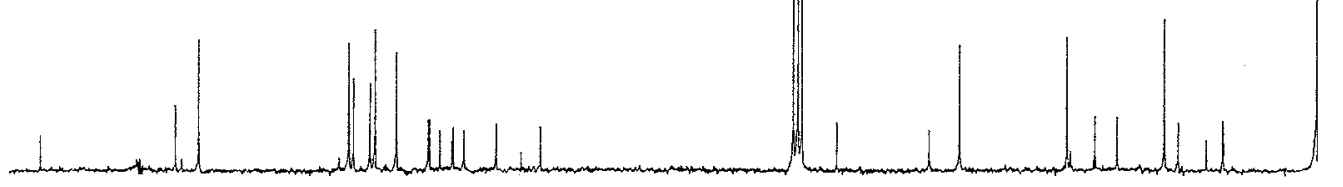

(B)

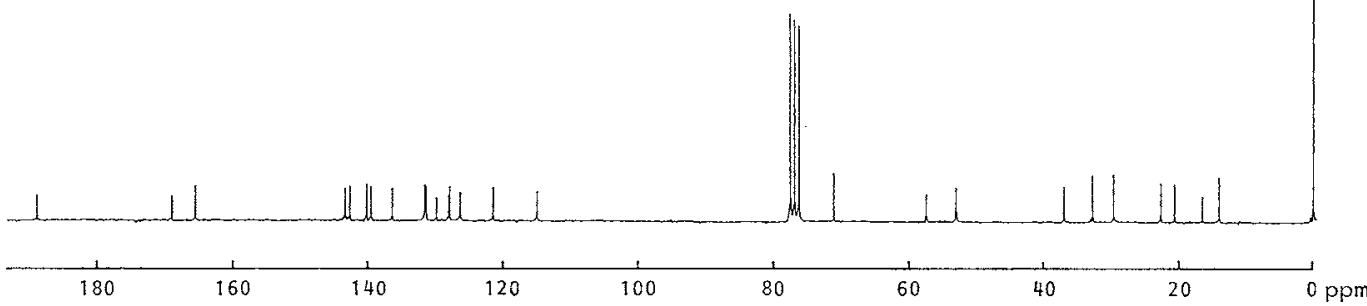


Scheme 1.

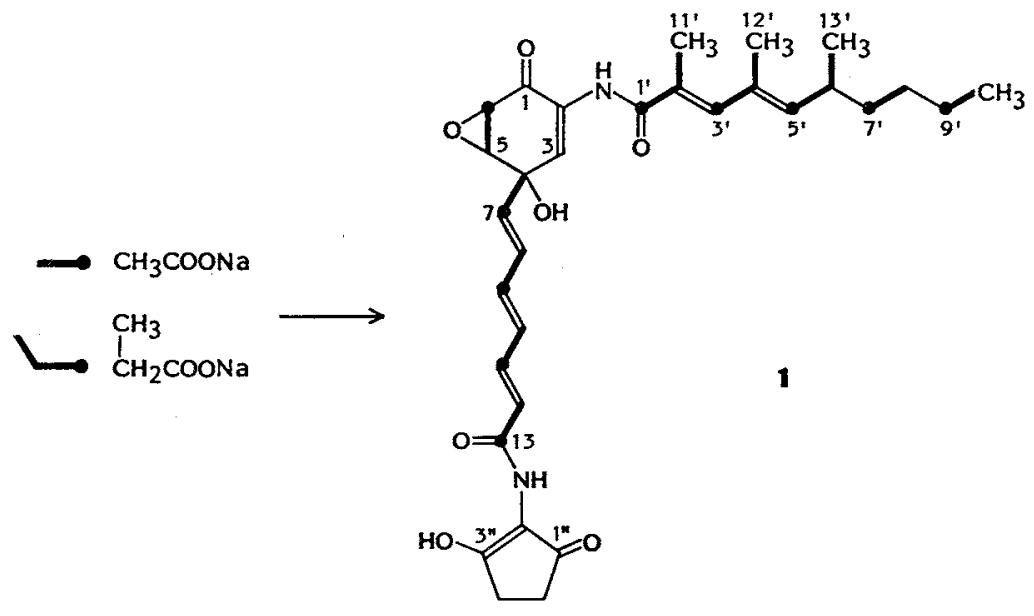

1 displayed the depicted labeling pattern (enhancements of the signals see Table 1). The $\mathrm{C}_{13}$-side chain was labeled by incorporation of $\left[1-{ }^{13} \mathrm{C}\right]$ acetate at positions $\mathrm{C}-1^{\prime}, \mathrm{C}-3^{\prime}, \mathrm{C}-5^{\prime}, \mathrm{C}-7^{\prime}$ and $\mathrm{C}^{-} \mathbf{9}^{\prime}$ indicating its polyketide origin. Feeding with $\left[2-{ }^{13} \mathrm{C}\right]$ acetate allowed us to clarify whether the methyl groups derive from acetate via propionyl-coenzyme $\mathrm{A}$ or from methionine. The significant enhancements of $\mathrm{C}-11^{\prime}, \mathrm{C}-12^{\prime}$ and $\mathrm{C}-13^{\prime}$ as well as the noticeable distribution of the label over the whole chain with the exception of $\mathrm{C}-7^{\prime}$ and $\mathrm{C}-9^{\prime}$ indicated the methyl group's polyketide origin. A feeding experiment with $\left[1 \sim^{13} \mathrm{C}\right]$ propionate $(99 \%$ enriched) with signal enhancements at C-1' $(988 \%), \mathrm{C}-3^{\prime}$ $(925 \%)$ and $\mathrm{C}-5^{\prime}(831 \%)$ proved this result. The not expected overall dilution of the $\left[2-{ }^{13} \mathrm{C}\right]-$ acetate label obviously is an indication of a highly active TCA-cycle. This suggested that the $\mathrm{C}_{13}$-side chain is assembled by a starter acetyl$\mathrm{CoA}\left(\mathrm{C}-9^{\prime}\right.$ and $\left.\mathrm{C}-10^{\prime}\right)$ and extended by one malonyl-CoA and three propionyl-CoA molecules. We believe further support of this pathway is provided by feeding experiments with unlabeled methionine $(10 \mathrm{mmol} / \mathrm{liter}$ and 0.1 $\mathrm{mmol} /$ liter) in which drastic inhibition of the secondary metabolism and lack of manumycin production is observed.

Furthermore, the ${ }^{13} \mathrm{C}$ signal enhancements of the all-trans triene chain of 1 at $\mathrm{C}-9, \mathrm{C}-11$ and $\mathrm{C}-13$ for $\left[1-{ }^{13} \mathrm{C}\right]$ acetate incorporation and at $\mathrm{C}-8$, $\mathrm{C}-10$ and $\mathrm{C}-12$ for $\left[2-{ }^{13} \mathrm{C}\right]$ acetate incorporation, are only explainable by polyketide metabolism.
Table 1. Chemical shifts and enhancements (standardized to the $\mathrm{C}-2^{\prime \prime}$ signal intensity) of the proton noise decoupled ${ }^{13} \mathrm{C}$ NMR resonances of manumycin (1) after feeding with $\left[1{ }^{13} \mathrm{C}\right]$ acetate and $\left[2-{ }^{33}\right.$ C]acetate.

Spectra recorded at $50.4 \mathrm{MHz}$.

\begin{tabular}{|c|c|c|c|}
\hline \multirow{2}{*}{ C-Atom } & \multirow{2}{*}{$\delta(\mathrm{ppm})$} & \multicolumn{2}{|c|}{ Enhancement (\%) } \\
\hline & & {$\left[1-{ }^{13} \mathrm{C}\right]$ Acetate } & {$\left[2-{ }^{13} \mathrm{C}\right]$ Acetate } \\
\hline 1 & 188.9 & +6.5 & +26.8 \\
\hline 2 & 128.0 & -19.7 & +12.0 \\
\hline 3 & 126.3 & -0.6 & +15.4 \\
\hline 4 & 71.3 & -32.3 & +71.0 \\
\hline 5 & 57.5 & +5.1 & +108.3 \\
\hline 6 & 52.9 & +138.4 & +76.1 \\
\hline 7 & 136.5 & +134.7 & +77.5 \\
\hline 8 & 131.5 & +4.0 & +98.6 \\
\hline 9 & 139.6 & +166.1 & +18.9 \\
\hline 10 & 131.7 & -5.9 & +85.1 \\
\hline 11 & 143.4 & +150.7 & +23.9 \\
\hline 12 & 121.6 & +0.1 & +80.3 \\
\hline 13 & 165.5 & +119.8 & -5.3 \\
\hline $1^{\prime}$ & 168.8 & +65.1 & +56.8 \\
\hline $2^{\prime}$ & 128.4 & -22.8 & +88.7 \\
\hline $3^{\prime}$ & 140.2 & +56.1 & +64.8 \\
\hline $4^{\prime}$ & 129.9 & +0.4 & +111.7 \\
\hline $5^{\prime}$ & 142.7 & +64.2 & +81.5 \\
\hline $6^{\prime}$ & 32.9 & -27.0 & +88.0 \\
\hline $7^{\prime}$ & 37.1 & +140.4 & +39.9 \\
\hline $8^{\prime}$ & 29.8 & -21.7 & +52.9 \\
\hline $9^{\prime}$ & 22.8 & +130.6 & +44.5 \\
\hline $10^{\prime}$ & 14.1 & -20.3 & +87.0 \\
\hline $11^{\prime}$ & 14.0 & -20.0 & +89.7 \\
\hline $12^{\prime}$ & 16.5 & -20.0 & +135.0 \\
\hline $13^{\prime}$ & 20.7 & -10.9 & +102.8 \\
\hline $2^{\prime \prime}$ & 115.0 & 0 & 0 \\
\hline
\end{tabular}


In addition, $\left[1-{ }^{13} \mathrm{C}\right]$ acetate was incorporated into the $m-\mathrm{C}_{7} \mathrm{~N}$ unit of 1 at $\mathrm{C}-6$ and $\mathrm{C}-7,\left[2-{ }^{13} \mathrm{C}\right]-$ acetate at C-4, C-5, C-6 and C-7, a fact of high distribution of the $\left[2-{ }^{13} \mathrm{C}\right]$ acetate label via the TCA-cycle, whereas the remaining three carbon atoms of this multifunctional ring showed no enhancements. The labeling pattern with the back to back association of two acetate molecules suggested succinate to be a likely biosynthetic precursor of the $m-\mathrm{C}_{7} \mathrm{~N}$ unit and a preliminary feeding experiment with $\left[1,4-{ }^{14} \mathrm{C}_{2}\right]$ succinate showed an incorporation rate of $2.5 \%$, but this might also be due to incorporation into the $\mathrm{C}_{5} \mathrm{~N}$-moiety ${ }^{7}$. The origin of the remaining three carbon atoms of the $m-C_{7} \mathrm{~N}$ unit is still under study ${ }^{8}$. The present results, however, lead to the prediction of a novel biosynthetic pathway for the $m-\mathrm{C}_{7} \mathrm{~N}$ unit found in the manumycin group antibiotics. This is in agreement with results recently reported in the case of asukamycin $^{9)}$.

\section{Acknowledgment}

We thank Prof. H. ZäHNER, Institut für Biologie II, der Universität Tübingen (FRG), for making available to us the strain Streptomyces parvullus (Tü 64).

\section{References}

1) SCHRÖDER, K. \& A. ZEECK: Manumycin. Tetrahedron Lett. 1973: 4995 4998, 1973

2) ZeECK, A.; K. Schröder, K. Frobel, R. Grote \& R. THIERICKE: The structure of manumycin.
I. Characterization, structure elucidation and biological activity. J. Antibiotics 40: 1530 1540,1987

3) Thiericke, R.; M. StellwaAG, A. Zeeck \& G. SNATZKE: The structure of manumycin. III. Absolute configuration and conformational studies. J. Antibiotics 40: 1549 1554, 1987

4) Kakinuma, K.; N. Ikekawa, A. Nakagawa \& S. OMURA: The structure of asukamycin, a possible shunt metabolite from 3-dehydroquinic acid in the shikimate pathway. J. Am. Chem. Soc. $101: 3402 \sim 3404,1979$

5) Slechta, L.; J. I. Claldella, S. A. Mizsak \& H. HoEksEma: Isolation and characterization of a new antibiotic U-62162. J. Antibiotics 35: $556 \sim 560,1982$

6) Brodasky, T. F.; D. W. Stroman, A. Dietz \& S. MizsaK: U-56,407, a new antibiotic related to asukamycin: Isolation and characterization. J. Antibiotics 36: 950 956, 1983

7) Nakagawa, A.; T. Shiang Wu, P. J. Keller, J.P. LEe, S. ÖMurA \& H. G. Floss: Biosynthesis of asukamycin. Formation of the 2amino-3-hydroxycyclopenten-2-one moiety. J. Chem. Soc. Chem. Commun. 1985: 519 521, 1985

8) Beale, J. M.; R. E. Herrold, H. G. Floss, R. Thiericke, A. ZeEcK, A. NakaGaWA \& $\mathrm{S}$. OMura: Studies on the biosynthesis of the $m e t a-\mathrm{C}_{7} \mathrm{~N}$ unit in the antibiotics manumycin and asukamycin. J. Am. Chem. Soc. 110: 1987, in press

9) Floss, H. G.; P. J. Keller \& J. M. Beale: Studies on the biosynthesis of antibiotic. J. Nat. Prod. 49: 957 970, 1986 